\title{
Temporal lobe seizures from a posterior cerebral artery aneurysm presenting as memory flashbacks
}

\author{
Mohamed A. Peera, MD, CM; ${ }^{*}$ Michael LoCurto, $\mathrm{MD}^{\dagger}$
}

\begin{abstract}
Memory flashbacks are usually attributed to recreational drugs or psychiatric conditions. The differential diagnosis for memory flashbacks is diverse and challenging; moreover, management is influenced by the working diagnosis. We describe the case of a 35-year-old man who presented with memory flashbacks secondary to temporal lobe seizures from an unruptured aneurysm of the posterior cerebral artery. To our knowledge, a case of this nature has not been previously reported. This case demonstrates the need to recognize that, on rare occasions, a complaint of memory flashbacks can be the result of an organic etiology. We also discuss the challenging presentations of temporal lobe seizures, as they can easily be misdiagnosed as a psychiatric condition.
\end{abstract}

\section{RÉSUMÉ}

On attribue généralement le phénomène des flashbacks à la consommation de drogues à usage récréatif ou à certaines maladies psychiatriques. Le diagnostic différentiel de ces flashbacks est multiple et complexe. Or, leur prise en charge dépend du diagnostic. Nous décrivons le cas d'un homme de 35 ans qui s'est présenté avec des flashbacks secondaires à des convulsions émanant du lobe temporal par suite d'un anévrisme non rompu de l'artère cérébrale postérieure. À notre connaissance, on n'avait encore jamais signalé de cas de cette nature, ce qui illustre la nécessité de reconnaître qu'en de rares occasions, les symptômes de flashbacks peuvent avoir une étiologie organique. Nous présentons également les tableaux complexes qui accompagnent les convulsions du lobe temporal puisqu'ils peuvent facilement passer à tort pour des pathologies psychiatriques.

Keywords: memory flashbacks, temporal lobe seizure, posterior cerebral artery, cerebral aneurysm

\section{INTRODUCTION}

Memory flashbacks are usually attributed to recreational drugs or posttraumatic stress disorder (PTSD), and have been defined as "unbidden, often vivid, images (or a sequence of images) that occur while a person is awake." These images are usually of a specific past event or experience. Hallucinogen persisting perception disorder (i.e., memory flashbacks) is defined by the Diagnostic and Statistical Manual of Mental Disorders, 4th edition, as memory flashbacks that are experienced with earlier hallucinogen intoxication. ${ }^{2}$ Temporal lobe seizures (TLS) have rarely been reported from structural brain defects, such as arteriovenous malformations and unruptured intracranial aneurysms. ${ }^{3-5}$ They may present with emotional lability, fear, memory flashbacks, visual hallucinations, altered consciousness or cognitive impairment, and can easily be mistaken for PTSD. ${ }^{3}$

\section{CASE REPORT}

A 35-year-old man presented to the emergency department (ED) with episodes of "going back in time" (memory flashbacks). He stated that 2 days before presenting to the ED, while talking to someone, he suddenly felt that he was "20 years back in time" and in his mind he actually re-experienced events that had transpired in his life previously. He reported that the episode lasted for only a few seconds, and then promptly resolved. Several such events were reported to have occurred during the 48 hours before his presentation. There was no witnessed seizure-like activity, postevent confusion or loss of consciousness. During the events, the patient described thoughts of people coming to harm him, nervousness and a general sense of being "unwell." He had no history of military experience, imprisonment, torture or abuse, life-threatening situations or experiences with unstable political situations. He denied psychiatric

From the *Department of Emergency Medicine, McGill University, Montréal, Que., and the †Department of Emergency Medicine, Long Island Jewish Medical Center, New Hyde Park, NY

Submitted Feb. 1, 2008; Revised Nov. 18, 2008; Accepted Dec. 29, 2008

This article has been peer reviewed

CJEM 2009;11(4):389-92 
illness, either personally or in the family, and was not suicidal or homicidal. He had no headaches, nausea or vomiting, weakness, numbness, difficulty with speech, visual problems, urinary or fecal incontinence, tonguebiting, alternation in mental status, fever or chills, or trauma. The patient reported some extra stress with his business affairs. He was in his usual state of health until 2 days before his presentation to the ED. His medical history was remarkable only for gastritis and anemia. His only medications were iron and folic acid. His family history and review of systems were unremarkable. The patient was born in Bangladesh, and had immigrated to the United States when he was 22 years old. $\mathrm{He}$ had visited India and Bangladesh numerous times, with his most recent visit to India 10 months before the presentation. There was no history of cigarette, alcohol or recreational drug use.

On physical examination, the patient appeared well, but slightly anxious. His vital signs were as follows: rectal temperature $36.5^{\circ} \mathrm{C}$, blood pressure $122 / 75 \mathrm{~mm} \mathrm{Hg}$, pulse 53 beats/min, respiratory rate 14 breaths/min and room air oxygen saturation $99 \%$. Except for bradycardia, the rest of the patient's physical examination, including cardiovascular, respiratory, abdominal, neurologic and skin, were normal. The patient was alert and oriented to time, place and person. Results of laboratory studies, including complete cell count, electrolytes, blood urea nitrogen, creatinine, glucose, liver and coagulation profiles, and urine toxicology were all normal. His electrocardiogram showed sinus bradycardia at a rate of 47 beats $/ \mathrm{min}$ and a chest radiograph was unremarkable.

Because the initial toxicologic screening was negative, and there was no personal or family history of psychiatric illness, we requested a computed tomography (CT) scan of the head to rule out a structural lesion that could explain our working diagnosis of nonconvulsing seizures. A neurologist was consulted to assess the patient and arrange an electroencephalogram (EEG). Computed tomography of the head showed a tubular hyperattenuating lesion within the left temporal lobe (Fig. 1). The patient was admitted to the neurology service with an admission diagnosis of probable TLS with a left temporal lobe mass. The patient's EEG confirmed TLS and he was started on levetiracetam (Keppra, UCB, The Epilepsy Company). The patient's hospital course was free of memory flashbacks following treatment with levetiracetam. We performed a subsequent workup to better define the brain mass with magnetic resonance imaging (MRI) and magnetic resonance angiography (MRA) of the brain. The MRI showed the left temporal lobe mass (Fig. 2) and the MRA revealed early termination of the left posterior cerebral artery (PCA), suggestive of a PCA aneurysm. A CT angiogram of the brain revealed a left PCA aneurysm, which was confirmed by a conventional cerebral angiogram (Fig. 3). The patient had uneventful endovascular coiling of the cerebral aneurysm and he continued to take levetiracetam. His hospital course was otherwise unremarkable and he was discharged home without any neurologic deficits. In comparing the pre- and postcoiling MRI of the brain, there was a reduction found in the size of the left PCA aneurysm.

\section{DISCUSSION}

The temporal lobe is the most eliptogenic region of the brain. ${ }^{6}$ Auras of TLS are extremely diverse, but certain patterns are common. They may be classified as psychic, somatosensory or autonomic phenomena. ${ }^{6}$ Examples of psychic auras include déjà vu (a sense of familiarity), jamais $v u$ (a sense of unfamiliarity), depersonalization (a feeling of detachment from oneself), derealization (a sense that surroundings appear unreal) and a feeling of fear or anxiety. ${ }^{6,7}$ Piloerection, sweating, changes in heart rate and epigastric aura (rising sensation from the

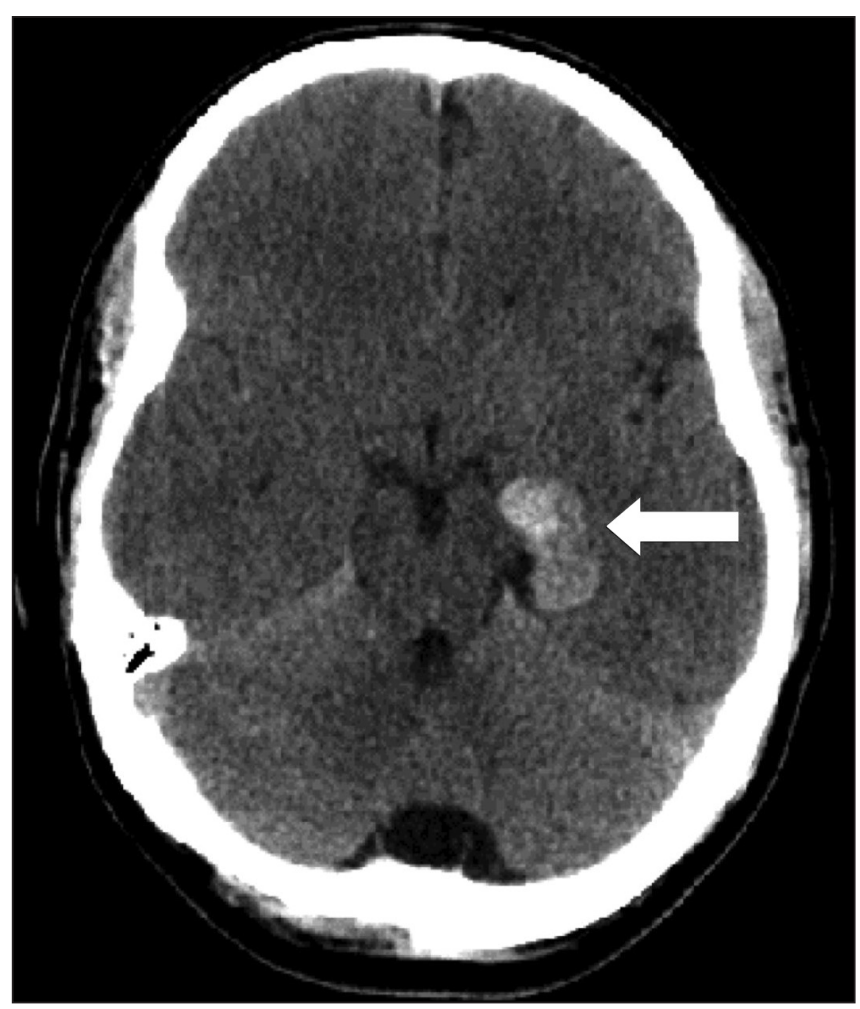

Fig. 1. Computed tomography scan of the head showing a tubular hyperattenuating lesion within the left temporal lobe. 
stomach) are examples of autonomic auras. ${ }^{6,7}$ Somatosensory auras include olfactory or gustatory illusions or hallucinations, visual illusions (distortions of shapes and sizes), auditory hallucinations and vertigo. ${ }^{6,7}$

Given the diverse presentation of TLS auras, the differential diagnosis of such presentations is broad and typically includes neurologic, toxicologic and psychiatric entities. The diverse presentation makes diagnosing nonconvulsive TLS challenging. Physicians must be cautious not to mislabel TLS with a psychiatric diagnosis, as doing so may affect the management of the patient and delay appropriate care.

Our top 3 differential diagnostic categories when approaching this case were toxicologic, psychiatric and nonconvulsive seizures. With a negative initial toxicologic and psychiatric assessment, nonconvulsive seizures emerged as our working diagnosis. The patient's symptoms of memory flashbacks and anxiety were auras associated with TLS. His bradycardia also suggested the possibility of autonomic changes that have been described with TLS. ${ }^{6}$ The head CT was ordered to identify any structural lesion that could explain our working diagnosis of nonconvulsing seizures.

The cerebral arterial circulation is divided into anterior and posterior divisions. The anterior circulation is formed by the carotid arteries and their branches, whereas the vertibrobasilar system forms the posterior circulation. Most cerebral aneurysms are located within the anterior

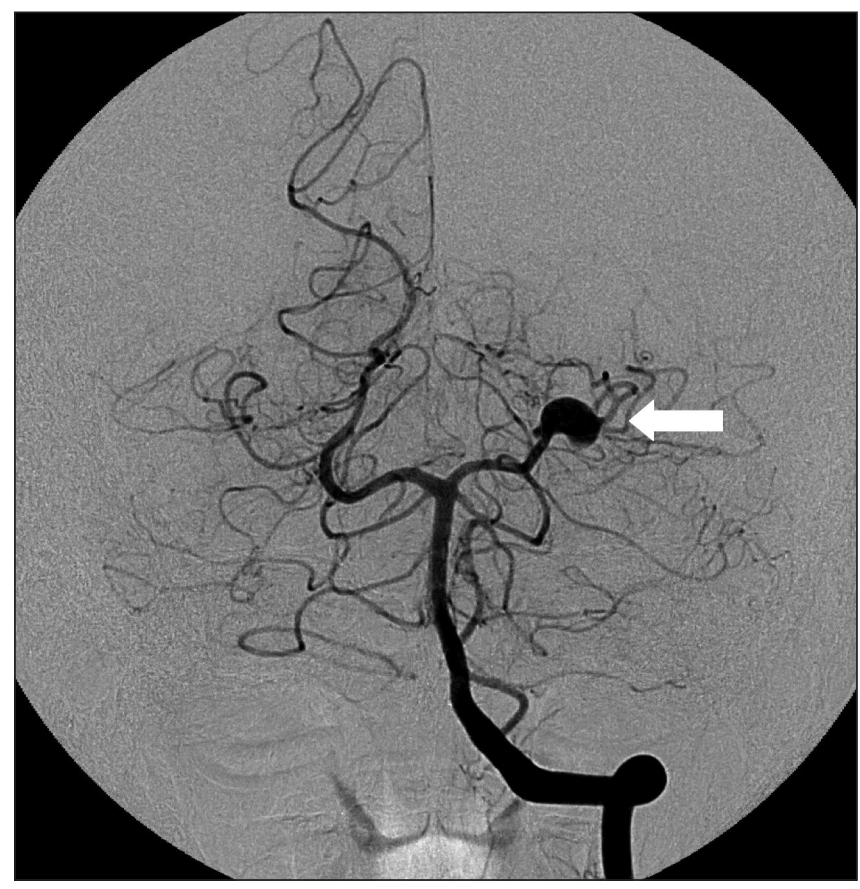

Fig. 3. Cerebral angiogram showing left posterior cerebral artery aneurysm.
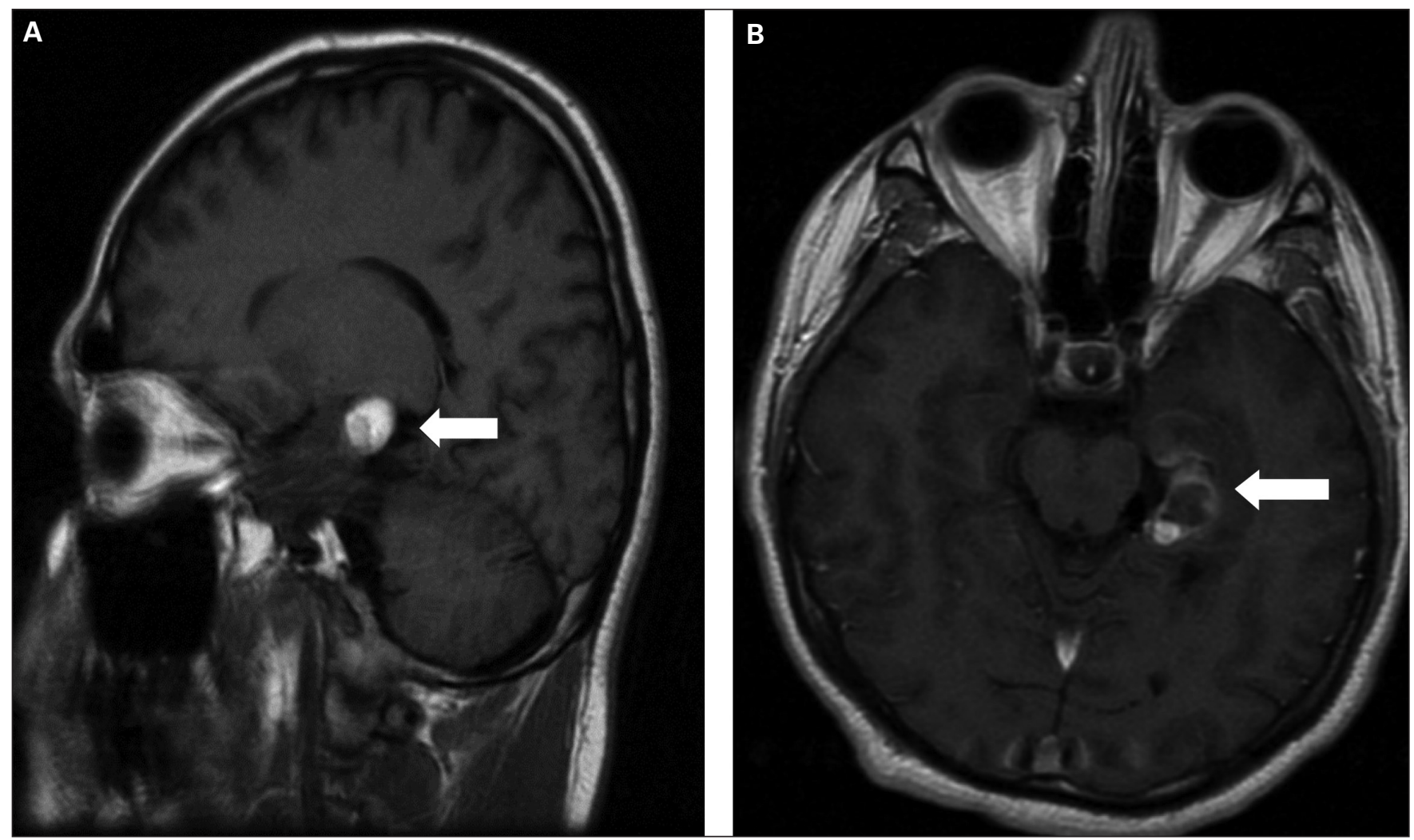

Fig. 2. Sagittal (A) and coronal (B) magnetic resonance imaging views of the brain showing the left temporal lobe mass. 
circulation. ${ }^{8,9}$ Posterior circulation aneurysms are rare, and account for only $10 \%$ of cerebral aneurysms. ${ }^{8,9}$ The PCAs arise from the vertibrobasilar system, and, hence, are classified as part of the posterior circulation. Aneurysms of the PCA are rare, making up only $1 \%$ of all cerebral aneurysms. ${ }^{10}$ The treatment options for unruptured cerebral aneurysm include observation, endovascular occlusion with the use of detachable coils (coiling), and craniotomy with clip ligation (clipping), ${ }^{8,9}$

\section{CONCLUSION}

Although memory flashbacks are usually associated with recreational drugs and PTSD, this case demonstrates that organic pathology can also present as memory flashbacks. Temporal lope seizures are a challenging presentation and may be misdiagnosed as a psychiatric disorder. Distinguishing organic from psychiatric pathology is challenging. An organic etiology is suggested by an acute presentation, abnormal vital signs, lack of psychiatric history, and disorientation. Longstanding similar presentations, normal vital signs, psychiatric history and normal mental status favours a psychiatric cause. When the distinction between organic and psychiatric pathology is not clear, a workup guided by the presentation is indicated.

Competing interests: None declared.

\section{REFERENCES}

1. Frankel FH. The concept of flashbacks in historical perspective. Int J Clin Exp Hypn 1994;42:321-36.

2. Hallucinogen persisting perception disorder (flashbacks). Diagnostic and statistical manual of mental disorders. 4th ed. Arlington (VA): American Psychiatric Association; 2000. p. 253-4.

3. Bennett TL, Curiel MP. Complex partial seizures presenting as a psychiatric illness: a case study. Int 7 Clin Neuropsychology 1988;10:41-4.

4. Leibrock LG, Bennett DR, Bloch S. Complex partial seizures associated with unruptured thrombosed basilar artery apex aneurysm. Surg Neurol 1983;19:17-20.

5. Tanaka K, Hirayama K, Hattori H., et al. A case of cerebral aneurysm associated with complex partial seizures. Brain Dev 1994;16:233-7.

6. Ko DY, Soma Sahai-Srivastava. Temporal lobe epilepsy. E-medicine 2006. Available: www.emedicine.com/NEURO /topic365.htm. (accessed 2009 May 19).

7. Zeeman A. Tales from the temporal lobes. $N$ Engl 7 Med 2005;352:119-21.

8. Brisman JL, Song JK, Newell DW. Cerebral aneurysm. NEngl 7 Med 2006;355:928-39.

9. Brisman JL, Soliman E, Kader A, et al. Cerebral aneurysm. E-medicine 2007. Available: www.emedicine.com/med /topic3468.htm (accessed 2009 May 19).

10. Svistov DV, Kandyba DV, Antonov SL. Embolization of large fusiform aneurysm of the posterior cerebral artery. Russian Neurosurgery 2001. Available: www.neuro.neva.ru /English/Issues/Articles_2_2001/svistov2.htm (accessed 2009 May 19)

Correspondence to: Dr. Mohamed Ali Peera, Department of Emergency Medicine, McGill University, Rm. A4.62, Royal Victoria Hospital, 687 Pine Ave. W., Montréal QC H3A 1A1; mohamed.peera@mail.mcgill.ca

\section{À LA RECHERCHE D'UN NOUVEL EMPLOI?}

En version imprimée et en ligne, la meilleure façon de placer une annonce ou de trouver un emploi en médecine d'urgence dans un contexte universitaire, administratif ou communautaire est par le biais du Journal canadien de la médecine d'urgence.

Version imprimée du $\mathcal{J C M U}$ : la date butoir pour placer une annonce dans la version imprimée du JCMU est un mois avant la date de parution de la revue. Pour connaître les tarifs pour les annonces et obtenir de plus amples renseignements, veuillez communiquer avec Beverly Kirkpatrick ou Deborah Rodd des Publications de l'AMC (800 663-7336 ou 613 731-8610 x2127 ou x2314, advertising@cma.ca).

\section{À LA RECHERCHE D'UN MÉDECIN D'URGENCE?}

PRIME SPÉCIALE : Les médecins qui placeront une annonce dans la version imprimée du JCMU recevront sans frais un espace pour leur annonce sur le site web de l'ACMU (www.caep.ca).

Site web de l'ACMU seulement : Pour placer une annonce sur le site web de l'ACMU seulement, le coût est de $100 \$$ par mois et l'annonce peut être placée en tout temps. Veuillez communiquer avec le siège social de l'ACMU pour les annonces sur le site web seulement (800 463-1158 ou advertising @caep.ca). 